\title{
Up-regulation of the CYP1 family in rat and human liver by the aliphatic isothiocyanates erucin and sulforaphane
}

\author{
Natalya Hanlon, *Nick Coldham, *Maurice J Sauer and Costas Ioannides
}

Centre of Toxicology, Faculty of Health and Medical Sciences, University of Surrey, Guildford, Surrey, GU2 7XH, and *Molecular Pathogenesis and Genetics, Veterinary Laboratories Agency-Weybridge, Woodham Lane, New Haw, Addlestone, Surrey,

KT15 3NB, UK

Key words: erucin - sulforaphane - isothiocyanates - chemoprevention cytochromes $\mathrm{P} 450$ - precision-cut slices

\section{Dedicated to the memory of George Gordon Gibson}

1949-2002

Corresponding author: Professor C Ioannides

Centre of Toxicology

Faculty of Health and Medical Sciences

University of Surrey

Guildford, Surrey

GU2 7XH, UK

Tel. No: +44 1483689709

Fax No: +44 1483686401 


\section{E-mail: c.ioannides@surrey.ac.uk}

\section{Abstract}

On the basis of animal studies, the chemopreventive activity of isothiocyanates has been linked to their ability to modulate carcinogen-metabolising enzyme systems, including cytochromes P450. However, the potential of isothiocyanates to influence these enzyme systems in human liver has not been investigated. We have evaluated the modulation of cytochrome P450 expression in two human liver samples by erucin and sulforaphane, in comparison to rat, following the incubation of precision-cut human and rat liver slices with the two isothiocyanates. Both compounds failed to influence cytochrome P450 activity, as exemplified by the dealkylations of methoxy-, ethoxy- and pentoxyresorufin, and benzyloxyquinoline, in either human or rat liver. Impairment of activity was, however, observed in some activities at high concentrations $(50 \mu \mathrm{M})$, which was attributed to toxicity. At the apoprotein level, however, both compounds elevated markedly CYP1A2/1B1 levels in rat liver, but in human liver only a modest increase was evident, and only in one of the livers. CYP3A2 apoprotein levels were modestly elevated in rat liver by both isothiocyanates both of which, however, failed to influence CYP3A4 expression in human liver. Neither isothiocyanate, in either rat or human liver, modulated CYP2B apoprotein levels. It may be inferred that (a) human and rat liver differ in their response to erucin and sulforaphane; (b) erucin and sulforaphane, despite being small molecular weight aliphatic compounds, up-regulate the CYP1 family but no increase in activity is observed as a result of mechanism-based inhibition, and (c) the chemopreventive effect of isothiocyanates, at dietary levels of intake, is unlikely to be due to inhibition of the cytochrome P450-mediated bioactivation of carcinogens. 


\section{Introduction}

Brassica vegetable consumption is increasingly being linked to low cancer incidence in epidemiological studies (Hecht, 2000; London et al., 2000; Ambrosone et al., 2004; Zhao et al., 2007; Higdon et al., 2007). Furthermore, isothiocyanates, which are encountered at substantial levels in these vegetables where they are present as glucosinolates, have also been linked to low cancer incidence (Lin et al., 1998; Spitz et al., 2000) and, in addition, they have been demonstrated repeatedly to afford protection against the carcinogenic effects of chemicals in laboratory studies in animal models (Hecht, 2000).

One of the most extensively studied isothiocyanates is sulforaphane [1isothiocyanato-4-(methylsulphinyl) butane], its principal source being broccoli, where it is encountered as the glucosinolate, glucoraphanin. Sulforaphane has been shown repeatedly to afford protection against chemical carcinogens in animal models of cancer (Zhang et al., 2004; Chung et al., 2000; Fahey et al., 2002; Shen et al., 2007). Erucin [1-isothiocyanato-4-(methylthio)-butane] is a structurally related isothiocyanate to sulforaphane, its principal source being rocket salad, and is also a major metabolic product of sulforaphane, at least in rat (Kassahun et al., 1997; Bheemreddy and Jeffery, 2007). In a number of studies erucin has been shown to share similar biological activity with sulforaphane (Jakubíková et al., 2005; Barillari et al., 2005; Hanlon et al., 2008a and b).

Isothiocyanates appear to interfere beneficially in all stages of chemical carcinogenesis (Conaway et al., 2002; Zhang, 2004). As far as initiation is concerned, they act by limiting the production of genotoxic metabolites, which is achieved in two ways. Firstly, they are believed to impair the cytochrome P450-mediated bioactivation 
of chemical carcinogens to their genotoxic intermediates and, secondly, they stimulate the detoxication of the genotoxic intermediates by up-regulating enzyme systems such as quinone reductase and glutathione S-transferases (Conaway et al., 2002; Zhang, 2004). At dietary levels of intake, the latter mechanism appears to predominate (Yoxall et al., 2005; Konsue and Ioannides, 2008; Hanlon et al., 2008a).

Modulation of the cytochrome P450 enzyme systems by erucin and sulforaphane has been investigated largely in rodents (Conaway et al., 1996; Barcelo et al., 1996; Yoxall et al., 2005; Hanlon et al., 2008a), and the assumption is made that humans are likely to respond similarly to the same doses, thus providing a feasible mechanism to explain epidemiological findings. Indeed, studies conducted in primary hepatocytes indicated the potential of sulforaphane to modulate cytochrome P450 expression in human liver (Maheo et al., 1997).

The principal aim of our studies was to investigate whether sulforaphane and erucin influence cytochrome $\mathrm{P} 450$ activity and expression in similar manner in rat and human liver. Our studies focussed, in particular, on CYP1 as this family of cytochrome P450 enzymes is the most active in the bioactivation of chemical carcinogens, including polycyclic aromatic hydrocarbons, aflatoxin $\mathrm{B}_{1}$ and heterocyclic amines (Ioannides and Parke 1990; Ioannides and Lewis 2004).To attain this objective, studies were conducted in precision-cut slices from the liver of rats and two human donors. The principal advantages of this in vitro system are that it maintains tissue architecture and cell-cell communication, and it allows the facile comparison of animal species exposed to a wide range of concentrations of chemicals, that would otherwise necessitate large animal numbers for commensurate in vivo studies (Lerche-Langrand and Toutain, 2000). Studies emanating from our and other laboratories have established that precision-cut slices are an appropriate system for 
use in evaluating the potential of xenobiotics to modulate cytochrome P450 activities in rodent and human liver (Lake et al 1993; Edwards et al 2003; Pushparajah et al 2007, 2008).

In this study we report for the first time modulation of cytochrome P450 expression and activity in human liver by erucin and sulforaphane, in comparison to rat, following incubation, under identical conditions, of precision-cut human and rat liver slices with the two isothiocyanates.

\section{Materials and Methods}

Sulforaphane and erucin (LKT Laboratories, Minnesota, USA), NADPH, ethoxyresorufin, pentoxyresorufin, resorufin, peroxidase-linked anti-rabbit and antigoat antibodies (Sigma Co. Ltd., Poole, Dorset, UK), 7-benzyloxyquinoline and 7hydroxyquinoline (BD Biosciences, California USA) were all purchased. Rat antiCYP1A1, recognising both CYP1A1 and CYP1A2, anti-CYP1B1, anti-CYP2B and anti-CYP3A2, which also recognises human CYP3A4, antibodies were obtained from BD Biochemicals (Oxford, UK).

Male Wistar albino rats (about $180 \mathrm{~g}$ ) were obtained from B\&K Universal Ltd (Hull, East Yorkshire, UK). The animals were housed at $22 \pm 2{ }^{\circ} \mathrm{C}, 30-40 \%$ relative humidity, in an alternating 12-hr light:dark cycle with light onset at $07.00 \mathrm{hr}$. Liver sections from two human cadaveric livers that could not be used for transplantation purposes were obtained from the UK Human Tissue Bank (The Innovation Centre, Oxford Street, Leicester, U.K). Both donors died following lethal brain injury. Donor 1 was a 26-year old male smoker who was maintained on ventilation for four days prior to death, whereas Donor 2 was a 54-year old non-smoking female who was maintained on artificial ventilation for two days prior to death ; both were Caucasian. 
Liver sections were transported in cold University of Wisconsin (UW) preservation solution on ice. The time interval from the moment of donors' death to the beginning of the incubation did not exceed $12 \mathrm{~h}$ on both occasions. On receipt, the liver sections were immediately transferred into a sterile container and, after the UW solution was carefully decanted, were washed 3 to 4 times with culture medium.

Rat and human liver slices $(250 \mu \mathrm{m})$ were prepared from $8 \mathrm{~mm}$ cylindrical cores using a Krumdieck tissue slicer (Alabama Research and Development Corporation, Munsford, AL, USA) as previously described (Hashemi et al., 1999). The multiwell plate procedure, using 12-well culture plates, was used to culture the slices. One slice was placed in each well, in $1.5 \mathrm{ml}$ of culture medium. Slices were incubated under sterile conditions on a reciprocating plate shaker housed in a humidified incubator, at a temperature of $37{ }^{\circ} \mathrm{C}$ and under an atmosphere of $95 \%$ air $/ 5 \% \mathrm{CO}_{2}$. The slices were initially pre-incubated for $30 \mathrm{~min}$ in order to slough off any dead cells due to slicing. Three different slice pools, each comprising 10-12 rat or human slices, were used per time point.

Following incubation, slices were removed from culture media, homogenised and post-mitochondrial supernatants prepared and stored at $-80^{\circ} \mathrm{C}$. When required, microsomes were isolated by centrifugation $(105000 \mathrm{~g}$ x 1 hour). The dealkylations of methoxy- (Burke and Mayer, 1983) ethoxy- (Burke and Mayer, 1983), pentoxyresorufin (Lubet et al., 1985) and 7-benzyloxyquinoline (Stresser et al., 2002), and protein content (Bradford, 1976) were determined. Finally, in order to monitor changes in enzyme protein expression, hepatic microsomal proteins were resolved by electrophoresis and incubated with the primary antibody and the corresponding peroxidase-linked secondary antibody. Immunoblots were quantitated by densitometry using the GeneTool software (Syngene Corporation, Cambridge, UK). 
Statistical evaluation was carried out employing Student's t-test.

\section{Results}

Incubation of rat liver slices with erucin had no effect on the various cytochrome P450-mediated dealkylations, except in the case of ethoxy- and methoxyresorufin where impairment of activity was observed, but only at the highest concentration (50 $\mu \mathrm{M})$ (Figure 1). Similarly, no statistically significant change was noted when rat liver slices were incubated with sulforaphane, except at the highest concentration studied $(50 \mu \mathrm{M})$ where the dealkylation of pentoxy- and methoxyresorufin were inhibited (Figure 2). However, both compounds markedly up-regulated CYP1A2 apoprotein levels, causing a trebling at an isothiocyanate concentration of $10 \mu \mathrm{M}$ (Figure 3). Both compounds also up-regulated CYP1B1 apoprotein levels, but the effect was less pronounced compared with CYP1A2 (Figure 3). A modest rise in apoprotein levels was evident when rat microsomes were probed with anti-CYP3A2; neither compound elevated CYP2B apoprotein levels (Figure 3).

A similar picture emerged in cytochrome P450 activities when human liver slices were incubated under identical conditions with the two isothiocyanates. No change in any of the activities studied was observed in either of the human livers when slices were incubated with erucin, except for a decrease in activity at high concentrations (Figure 4). Similar observations were made when erucin was replaced with sulforaphane (Figure 5). Both compounds elevated modestly, in comparison to rat, CYP1A1 and CYP1B1 apoprotein levels in Donor 2, but not in Donor 1 (Figure 6). Finally, neither compound modulated CYP2B or CYP3A4 apoprotein levels in either human liver, but a fall in levels was evident at the higher concentrations. 


\section{Discussion}

Experimental studies in animals led to the conclusion that a mechanism through which isothiocyanates may exert their chemopreventive activity is suppression of the cytochrome P450-mediated bioactivation of chemical carcinogens (Conaway et al., 2002). To evaluate whether the same mechanism is operative in humans, studies were undertaken utilising precision-cut slices incubated with erucin and sulforaphane, two aliphatic isothiocyanates; similar studies were conducted in slices from rats, as the anticarcinogenic activity of this class of compounds has been established largely in this animal species. The study focussed on CYP1, undoubtedly the most active cytochrome P450 family in carcinogen bioactivation (Ioannides and Lewis, 2004; Ioannides and Parke, 1990), and the CYP2B subfamily, which is active in the bioactivation of nitrosamines (Shu and Hollenberg, 1997). Finally, as CYP3A4 is the dominant enzyme in the metabolism of drugs, the effect of erucin and sulforaphane on the hepatic levels of this enzyme was also monitored in order to assess whether interactions with drugs are likely to occur. Liver slices have been incubated with the isothiocyanates in question for 24 hours as previous studies have established that maximum induction is achieved at this time point (Pushparajah et al., 2007).

In our previous studies, confined to hepatic phase II enzyme systems, we identified species differences when comparing the effects erucin and sulforaphane in human and rat liver (Hanlon et al., 2008b); consequently, current studies were conducted in both species. In rat, both compounds elevated the levels of both CYP1A2 and CYP1B1 markedly, in concentration-dependent manner. In contrast, there was no effect, at the same concentrations, on the dealkylations of ethoxy- and methoxy-resorufin activities which are catalysed by the CYP1 family (Namkung et 
al., 1988), confirming the outcome of our previous in vivo studies (Hanlon et al., 2008a; Yoxall et al., 2005). This lack of concordance is most likely due to the fact that both these compounds are effective mechanism-based inhibitors of cytochrome P450 activity (Yoxall et al., 2005; Hanlon et al., 2008a). A cytochrome P450mediated metabolite, believed to be an isocyanate (Lee, 1996; Goosen et al., 2001), interacts covalently with the enzyme rendering it catalytically incompetent. Both compounds failed to similarly up-regulate CYP2B either at the activity, as exemplified by the depentylation of pentoxyresorufin (Namkung et al., 1988), or at the apoprotein level, whereas in the case of CYP3A2 there was modest rise in apoprotein levels but no effect on the associated activity of benzyloxyquinoline dealkylation (Stresser et al., 2002). Clearly, the effects of erucin and sulforaphane on the rat hepatic cytochrome P450 system are isoform-specific. It is pertinent to point out that CYP1 up-regulation was not confined to the liver, but was also manifested when rat lung slices were exposed to the same concentrations of these isothiocyanates (unpublished observations). It is also relevant to emphasise that following oral administration of sulforaphane to rats, at the dietary dose of $0.5 \mathrm{mg} / \mathrm{kg}$, the peak plasma concentrations achieved were $<0.3 \mu \mathrm{M}$ i.e. below the lowest concentration employed in the present study (Hanlon et al., 2008c), and modulation of cytochrome P450 expression at this level is improbable.

At the highest concentration studied, both compounds suppressed cytochrome P450 activity. We believe this is the result toxicity, which is associated with depletion of glutathione (Hanlon et al., 2008b), as a result of its utilisation in the metabolism of the isothiocyanate. At this concentration we have reported toxicity in rat liver slices as reflected by increased leakage of lactate dehydrogenase. 
The effects of erucin and sulforaphane on cytochrome P450 expression were clearly much less pronounced in human liver slices compared with the observations made in rat slices, incubated with the isothiocyanates under identical conditions. As in the rat, none of the enzymes studied was modulated by either isothiocyanate; the inhibition seen at higher concentrations is, once again, most likely the consequence of toxicity, as at this concentration glutathione is similarly depleted in human liver slices as in rat (Hanlon et al., 2008b). At the apoprotein level, however, both compounds failed to markedly up-regulate levels as observed in the rat. Neither isothiocyanate had any effect on CYP1A2 and CYP1B1 apoprotein levels in the liver from Donor 1, but in the case of Donor 2 both compounds elevated expression of these enzymes, but much less effectively compared with rat. These observations point to a possible species difference in the up-regulation of CYP1 by these isothiocyanates; however, more human samples need to be investigated for an unequivocal conclusion to be drawn. Moreover, the presence of a polymorphism in the up-regulation of CYP1 in humans can not be excluded; the Ah receptor, which controls the up-regulation of CYP1 expression (Denison and Nagy, 2003), is polymorphically expressed in humans, although the impact of these alleles on the induction of CYP1 proteins is not entirely clear (Harper et al., 2002; Koyano et al., 2005).

The up-regulation of the CYP1 family by erucin and sulforaphane was an unexpected and surprising observation, as these are small molecular weight aliphatic compounds, and thus atypical inducers of this cytochrome P450 family. Extensive studies have shown that the inducers of the CYP1 family are essentially aromatic planar compounds, characterised by a large area/depth ${ }^{2}$ ratio (Lewis et al., 1986; 1987). The most avid ligand to this receptor is the toxin TCDD $(2,3,7,8$ tetrachlorodibenzo-p-dioxin), and strong agonists are mostly large hydrophobic planar 
aromatic compounds such as the polycyclic aromatic hydrocarbons (Cheung et al 1993; Machala et al., 2001; Denison and Nagy, 2003; Pushparajah et al., 2007), although compounds comprising a single substituted aromatic ring, such as diaminotoluenes, can also serve as agonists (Cheung et al., 1996). Erucin and sulforaphane, both small molecular weight aliphatic compounds, are clearly strong inducers of CYP1 family expression despite the fact that structurally they are unlikely to be Ah receptor agonists. However, it should be borne in mind that up-regulation of the CYP1 family, independent of binding to the Ah receptor, has been reported (Ayalogu et al, 1995; Boyd et al, 1995; Lesca et al., 1995).

In conclusion, we have demonstrated that in rat liver the small molecular weight aliphatic isothiocyanates, erucin and sulforaphane, up-regulate the CYP1 family but the enzyme is not catalytically competent presumably due to mechanismbased inhibition. The induction potency of these isothiocyanates was similar, so that it is likely that the effect of sulforaphane in the rat may be partly mediated by erucin, its major metabolite, at least in the rat (Kassahun et al., 1997; Bheemreddy and Jeffery, 2007). Similar studies in livers from two human donors showed, however, only a relatively modest rise in CYP1 expression in one of the livers with no effect on the other, alluding to a species difference. Finally, our observations allow us to infer that the chemopreventive effect of these isothiocyanates, at least at dietary levels of intake, is unlikely to be due to inhibition of cytochrome P450 carcinogen activation, but may involve primarily enhanced detoxification of reactive intermediates (Hanlon et al 2008a, 2008b).

\section{Acknowledgements}


The authors acknowledge with gratitude the financial support of the Association for International Cancer Research, and thank the UK Human Tissue Bank (The Innovation Centre, Leicester, UK) for the provision of the fresh human liver samples.

\section{References}

Ambrosone, C.B., McCann, S.E., Freudenheim, J.L., Marshall, J.R., Zhang, Y., Shields, P.G., 2004. Breast cancer risk in premenopausal women is inversely associated with consumption of broccoli, but is not modified by GST genotype. J. Nutr. 134, 1134-1138.

Ayalogu, E.O., Snelling, J., Lewis, D.F.V., Talwar, S., Clifford, M.N., Ioannides, C., 1995. Induction of hepatic CYP1A2 by the oral administration of caffeine to rats: Lack of association with the Ah locus. Biochim. Biophys. Acta 1272, 89-94.

Barcelo, S., Gardiner, J.M., Gescher, A., Chipman, J.K., 1996. CYP2E1-mediated mechanism of anti-genotoxicity of the broccoli constituent sulforaphane. Carcinogenesis 17, 277-282.

Barillari, J., Canistro, D., Paolini, M., Ferroni, F., Pedulli, G.F., Iori, R., Valgimigli, L., 2005. Direct antioxidant activity of purified glucoerucin, the dietary secondary metabolite contained in rocket (Eruca sativa Mill.) seeds and sprouts. J. Agric. Food Chem. 53, 2475-2482.

Bheemreddy, R.M., Jeffery, E.H., 2007. The metabolic fate of purified glucoraphanin in F344 rats. J. Agric. Food Chem. 55, 2861-2866. 
Boyd, G.W., Coombs, M.M., Ioannides, C., 1995. Induction, binding to the hepatic aromatic hydrocarbon receptor and mutagenicity of a series of 11-alkoxy cyclopenta[a]phenanthren-17-ones: A structure activity relationship. Toxicology 95, $27-35$

Bradford, M.M., 1976. A rapid and sensitive method for the quantitation of microgram quantities of protein utilising the principle of protein-dye binding. Anal. Biochem. 72, 248-254.

Burke, M.D., Mayer, R.T., 1974. Ethoxyresorufin: direct fluorimetric assay of a microsomal O-dealkylation which is preferentially inducible by 3methylcholanthrene. Drug Metab. Disp. 2, 583-588.

Burke, M.D., Mayer, R.T., 1983. Differential effects of phenobarbitone and 3methylcholanthrene induction on the hepatic microsomal and cytochrome P450 binding of phenoxazone and a homologous series of its n-alkyl ethers (alkoxyresorufins). Chem. Biol. Inter. 45, 243-258.

Cheung, Y.L., Gray, T.J., Ioannides, C., 1993. Mutagenicity of chrysene, its methyl and benzo derivatives, and their interactions with cytochromes P-450 and the Ahreceptor; relevance to their carcinogenic potency. Toxicology 81, 69-86.

Cheung, Y-L., Snelling, J., Mohammed, N.N.D., Gray, T.J.B., Ioannides, C., 1996. Interaction with the aromatic hydrocarbon receptor, CYP1A induction, and 
mutagenicity of a series of diaminotoluenes: implications for their carcinogenicity. Toxicol. Appl. Pharmacol. 139, 203-211.

Chung, F.-L., Conaway, C.C., Rao, C.V., Reddy, B.S., 2000. Chemoprevention of aberrant crypt foci in Fischer rats by sulforaphane and phenethyl isothiocyanate. Carcinogenesis 21, 2287-2291.

Conaway, C.C., Jiao, D., Chung, F.L., 1996. Inhibition of rat liver cytochrome P450 enzymes by isothiocyanates and their conjugates: a structure-activity relationship study. Carcinogenesis 17, 2423-2427.

Conaway, C.C., Yang, Y.-m., Chung, F.-L., 2002. Isothiocyanates as cancer chemopreventive agents: Their biological activities and metabolism in rodents and humans. Curr. Drug Met. 3, 233-255.

Denison, M.S., Nagy, S.R., 2003. Activation of the aryl hydrocarbon receptor by structurally diverse exogenous and endogenous chemicals. Annu. Rev. Pharmacol. Toxicol. 43, 309-334.

Edwards, R.J, Price, R.J., Watts, P.S., Renwick, A.B., Tredger, J.M., Boobis, A.R., Lake, B.G., 2003. Induction of cytochrome P450 enzymes in cultured precision-cut human liver slices. Drug Met. Disp. 31, 282-288.

Fahey, J.W., Haristoy, X., Dolan, P.M., Kensler T.W., Scholtus, I., Stephenson, K.K., Talalay, P., Lozniewski, A.. 2002. Sulforaphane inhibits extracellular, intracellular, 
and antibiotic-resistant strains of Helicobacter pylori and prevents benzo[a]pyreneinduced stomach tumors. Proc. Natl. Acad. Sci. 99, 7610-7615.

Goosen, T.C., Mills, D.E. and Hollenberg. P.F., 2001. Effects of benzyl iosothiocyanate on rat and human cytochromes P450: identification of metabolites formed by P450 2B1. J. Pharmacol. Exptl. Ther. 296, 198-206.

Hanlon, N., Okpara, A., Coldham, N., Sauer, M.J., Ioannides, C., 2008a. Modulation of rat hepatic and pulmonary cytochromes P450 and other xenobiotic-metabolising enzyme systems by the isothiocyanate erucin, a metabolite of sulforaphane. J. Agri. Food Chem., In Press.

Hanlon, N., Poynton, C.L., Coldham, N., Sauer, M.J., Ioannides, C., 2008b. The aliphatic isothiocyanates erucin and sulforaphane do not effectively up-regulate quinone reductase in human liver compared with rat. Submitted

Hanlon, N., Coldham, N., Gielbert, A., Kuhnert, N., Sauer, M.J., King, L.J., Ioannides, C., 2008c. Absolute bioavailability and dose-dependent pharmacokinetic behaviour of dietary doses of the chemopreventive isothiocyanate sulforaphane in rat. Br. J. Nutr. 99, 559-64.

Harper, P.A., Wong, J.Y., Lam, M.S., Okey, A.B., 2002. Polymorphisms in human AH receptor. Chem.-Biol. Interact. 141, 161-187. 
Hashemi, E., Dobrota, M., Till. C., Ioannides, C., 1999. Structural and functional integrity of precision-cut liver slices in xenobiotic metabolism: a comparison of the dynamic organ and multiwell plate culture procedures. Xenobiotica 29, 11-25.

Hecht, S.S., 2000. Inhibition of carcinogenesis by isothiocyanates. Drug Met. Rev. 32, $395-411$

Higdon, J.V., Delage, B., Williams, D.E., Dashwood, R.H., 2007. Cruciferous vegetables and human cancer risk. Pharmacol. Res. 55, 224-236.

Ioannides, C., Lewis, D.F.V., 2004. Cytochromes P450 in the bioactivation of chemicals. Curr. Topics Medicin. Chem. 4, 1767-1788.

Ioannides, C., Parke, D.V., 1990. The cytochrome P450 I gene family of microsomal haemoproteins and their role in the metabolic activation of chemicals. Drug Met. Rev. 22, 1-85.

Jakubíková, J., Sedlák, J., Mithen, R., Bao, Y., 2005. Role of PI3K/Akt and MEK/ERK signaling pathways in sulforaphane- and erucin-induced phase II enzyme and MRP2 transcription, $\mathrm{G}_{2} / \mathrm{M}$ arrest and cell death in Caco-2 cells. Biochem. Pharmacol. 69, 1543-1552.

Kassahun, K., Davis, M., Hu, P., Martin, B., Baillie, T., 1997. Biotransformation of the naturally occurring isothiocyanate sulforaphane in the rat: Identification of phase I metabolites and glutathione conjugates. Chem. Res. Toxicol. 10, 1228-1233. 
Konsue, N., Ioannides, C., 2008. Tissue differences in the modulation of rat cytochromes P450 and phase II conjugation systems by dietary doses of phenethyl isothiocyanate. Submitted.

Koyano, S., Saito, Y., Fukushima-Uesaka, J., Ishida, S., Ozawa, S., Kamatani, M., Minami, H., Ohtsu, A., Hamaguchi, T., Shirao, K., Yoshida, T., Saijo, N., Jinno, H., Sawada, J.-I., 2005. Functional analysis of six aryl hydrocarbon receptor variants in a Japanese population. Drug Met. Disp. 33, 1254-1260.

Lake, B.G., Beamand, J.A., Japenga, A.C., Renwick, A., Davies, S., Price, R.J., 1993., Induction of cytochome P-450-dependent enzyme activities in cultured rat slices. Food Chem. Toxicol. 31, 377-386.

Lee, M-S., 1996. Enzyme induction and comparative oxidative desulfuration of isothiocyanates to isocyanates. Chem. Res. Toxicol. 9, 1072-1078.

Lerche-Langrand, C., Toutain, H.J., 2000. Precision-cut liver slices: characteristics and use for in vitro pharmaco-toxicology. Toxicology 153, 221-253.

Lesca, P., Peryt, B., Larrieu, G., Alvinerie, M., Galtier, P., Daujat, M., Maurel, P., 1995. Evidence for the ligand-independent inactivation of the AH receptor. Biochem. Biophys. Res. Commun. 209, 474-482 
Lewis, D.F.V., Ioannides, C., Parke, D.V., 1986. Molecular dimensions of the substrate binding site of cytochrome P-448. Biochem. Pharmacol. 35, 2179-2185.

Lewis, D.F.V., Ioannides, C., Parke, D.V., 1987. Structural requirements for substrates of cytochromes P-450 and P-448. Chem.-Biol. Inter. 64, 39-60.

Lin, H.J., Probst-Hensch, N.M., Louie, A., Kau, I.H., Witte, J.S., Ingles, S.A., Frank, H.D., Lee, E.R., Haile, R.W., 1998. Glutathione transferase null genotype, broccoli, and lower prevalence of colorectal adenomas. Cancer Epidemiol. Biomarkers Prev. 7, 647-652.

London, S.J., Yuan, J.M., Chung, F.L., Gao, Y.T., Coetzee, G.A., Ross, R.K., Yu, M.C., 2000. Isothiocyanates, glutathione S-transferase M1 and T1 polymorphisms, and lung cancer risk: a prospective study in Shanghai, China. Lancet 356, 724-729.

Lubet, R.A, Mayer, R.T., Cameron, J.W., Nims, R.N., Burke, M.D., Wolf, T., Guengerich F., 1985. Dealkylation of pentoxyresorufin: a rapid and sensitive assay for measuring induction of cytochrome(s) P450 by phenobarbital and other xenobiotics in the rat. Arch. Biochem. Biophys. 238, 43-48.

Machala, M., Vondracek, J., Blaha, L., Ciganek, M., Neca, J., 2001. Aryl hydrocarbon receptor-mediated activity of mutagemic polycyclic aromatic hydrocarbons determined using in vitro reporter gene assay. Mutat. Res. 497, 49-62. 
Maheo, K., Morel, F., Langouët, S., Kramer, H., Le Ferrec, E., Ketterer, B., Guillouzo, A., 1997. Inhibition of cytochrome P-450 and induction of glutathione Stransferases by sulforaphane in primary human and rat hepatocytes. Cancer Res. 57, 3649-3652.

Namkung, M.J., Yang, H.L., Hulla, J.E., Juchau, M.R., 1988. On the substrate specificity of cytochrome P450IIIA1. Mol. Pharmacol. 34, 628-637.

Pushparajah, D.S., Umachandran, M., Nazir, T., Plant, K.E., Plant, N., Lewis, D.F.V., Ioannides, C., 2008. Up-regulation of CYP1A/B in rat lung and liver, and human precision-cut slices by a series of polycyclic aromatic hydrocarbons; association with the Ah locus and importance of molecular size. Toxicol. In Vitro 22, 128-145.

Pushparajah, D.S., Umachandran, M., Plant, K.E., Plant, N., Ioannides, C., 2007. Evaluation of the precision-cut liver and lung slice systems for the study of induction of CYP1, epoxide hydrolase and glutathione S-transferase activities. Toxicology 231, $68-80$.

Shen, G., Khor, T.O., Hu, R., Yu, S., Nair, S., Ho, C.T., Reddy, B.S., Huang, M.T., Newmark, H.L., Kong, A.N., 2007. Chemoprevention of familial adenomatous polyposis by natural dietary compounds sulforaphane and dibenzoylmethane alone and in combination in ApcMin/+ mouse. Cancer Res. 67, 9937-9944.

Shu, L., Hollenberg, P.F., 1997. Alkylation of cellular macromolecules and target specificity of carcinogenic nitrosodialkylamines: metabolic activation by cytochromes P450 2B1 and 2E1. Carcinogenesis 18, 801-810. 
Spitz, M.R., Duphorne, C.M., Detry, M.A., Pillow, P.C., Amos, C.I., Lei, L., de Andrade, M., Gu, X.J., Hong, W.K., Wu, X.F., 2000. Dietary intake of isothiocyanates: Evidence of a joint effect with glutathione S-transferase polymorphisms in lung cancer risk. Cancer Epidemiol. Biomark. Prev. 9, 1017-1020.

Stresser, D.M., Turner, S.D., Blanchard, A.P., Miller, V.P., Crespi, C.L., 2002. Cytochrome P450 fluorimetric substrates: identification of isoform-selective probes for rat CYP2D2 and human CYP3A4. Drug Met. Disp. 30, 845-852.

Yoxall, V., Kentish, P., Coldham, N., Kuhnert, N., Sauer, M.J., Ioannides, C., 2005. Modulation of hepatic cytochromes P450 and phase II enzymes by dietary doses of sulforaphane in rats: Implications for its chemopreventive activity. Int. J. Cancer 117, $356-362$.

Zhang, Y., 2004. Cancer-preventive isothiocyanates: measurement of human exposure and mechanism of action. Mut. Res. 555, 173-190.

Zhang, Y., Kensler, T.W., Cho, C.G., Posner, G.H., Talalay, P., 2004. Anticarcinogenic activities of sulforaphane and structurally related synthetic norbornyl isothiocyanates. Proc. Natl. Acad. Sci. 91, 3147-3150.

Zhao, H., Grossman, H.B., Hernandez, L.M., Dinney, C.P., Wu, X., 2007. Dietary isothiocyanates, GSTM1, GSTT1, NAT2 polymorphisms and bladder cancer risk. Int. J. Cancer 120, 2208-2213. 


\section{Legends to figures}

Figure 1: Effect of erucin on cytochromes $\mathbf{P 4 5 0}$ in precision-cut rat liver slices.

Liver slices were incubated in modified RPMI 1640 culture medium containing erucin (0 to $50 \mu \mathrm{M}$ ) for $24 \mathrm{~h}$. EROD (A), MROD (B), PROD (C) and 7-BQ (D) activities were determined in the microsomal fraction. Values represent the means $\pm \mathrm{SD}$ of 3 pools of slices, with each analysis performed in duplicate. ${ }^{*} \mathrm{P}<0.05, * * \mathrm{P}<0.01$ and $* * * \mathrm{P}<0.001$.

Figure 2: Effect of sulforaphane on cytochromes $\mathbf{P 4 5 0}$ in precision-cut rat liver slices.

Liver slices were incubated in modified RPMI 1640 culture medium containing sulforaphane (0 to $50 \mu \mathrm{M}$ ) for $24 \mathrm{~h}$. EROD (A), MROD (B), PROD (C) and 7-BQ (D) activities were determined in the microsomal fraction. Values represent the means \pm SD 3 pools of slices, with each analysis performed in duplicate. ${ }^{*} \mathrm{P}<0.05$, $* * \mathrm{P}<0.01$ and $* * * \mathrm{P}<0.001$

Figure 3: Modulation by erucin (A) and sulforaphane (B) of cytochrome P450 apoprotein levels in precision-cut liver slices.

Liver slices were incubated in modified RPMI 1640 culture medium containing either erucin or sulforaphane ( 0 to $50 \mu \mathrm{M})$ for $24 \mathrm{~h}$. Hepatic microsomal proteins were resolved by $10 \%(\mathrm{w} / \mathrm{v})$ SDS-PAGE and then transferred electrophoretically to Hybond-P polyvinylidene difluoride membranes. Immunoblot analysis was carried out using rat antibodies to cytochrome P450 proteins, followed by the appropriate peroxidase-labelled secondary antibody. Each lane was loaded with 10 (CYP2B1 and CYP3A2) or $40 \mu \mathrm{g}$ (CYP1A and CYP1B1) of total protein. Molecular markers were 
run concurrently to aid band identification. The values in italics show percentage optical density relative to control.

Figure 4: Effect of erucin on cytochromes P450 in precision-cut human liver slices

Slices were generated from the livers of two donors and incubated in modified RPMI 1640 culture medium containing erucin $(0$ to $50 \mu \mathrm{M})$ for $24 \mathrm{~h}$. The activities of EROD, MROD and 7-BQ demethylase were determined in the microsomal fraction using ethoxyresorufin (A), methoxyresorufin (B) and 7-benzyloxyquinoline (C) as substrates. Values represent the means \pm SD of 3 pools of slices, with each analysis performed in duplicate. $* \mathrm{P}<0.05, * * \mathrm{P}<0.01$ and $* * * \mathrm{P}<0.001$.

Figure 5: Effect of sulforaphane on cytochromes P450 in precision-cut human liver slices

Slices were generated from the livers of two donors and incubated in modified RPMI 1640 culture medium containing sulforaphane $(0$ to $50 \mu \mathrm{M})$ for $24 \mathrm{~h}$. The activities of EROD (A), MROD (B) and 7-BQ demethylase (C) were determined in the microsomal fraction. Values represent the means \pm SD of 3 pools of slices, with each analysis performed in duplicate. ${ }^{*} \mathrm{P}<0.05$, $* * \mathrm{P}<0.01$ and $* * * \mathrm{P}<0.001$.

Figure 6: Modulation of cytochrome P450 apoprotein levels by erucin and sulforaphane in human liver.

Slices from two human livers were incubated in modified RPMI 1640 culture medium containing erucin or sulforaphane $(0$ to $50 \mu \mathrm{M})$ for $24 \mathrm{~h}$. Hepatic microsomal proteins were resolved by $10 \%(\mathrm{w} / \mathrm{v})$ SDS-PAGE and then transferred electrophoretically to Hybond-P polyvinylidene difluoride membranes. Immunoblot analysis was carried out using rat antibodies to cytochrome P450 enzymes, followed by the appropriate 
peroxidase-labelled secondary antibody. Each lane was loaded with 20 (CYP1A and CYP3A4) or $40 \mu \mathrm{g}(\mathrm{CYP} 2 \mathrm{~B} 1 \mathrm{and}$ CYP1B1) of total protein. Molecular markers were run concurrently to aid band identification. The values in italics show percentage optical density relative to control.

\section{Conflict of interest}

The authors declare that there are no conflicts of interest 